\title{
Application and Research of Case Teaching in Management Information System Course
}

\author{
Zhiguo $\mathrm{Du}^{1, \mathrm{a}}$ and Dahui $\mathrm{Hu}^{1, \mathrm{~b}^{*}}$ \\ ${ }^{1}$ Business school of Southwest University, China \\ adu_zhiguo@hotmail.com, bhudahui@hotmail.com \\ * The Corresponding Author
}

Keywords: Management information system; Case teaching; curriculum design; Project analysis

\begin{abstract}
Management information system is one of the core courses of management specialty, and it is a new frontier subject. The content of the course is closely related to the modern enterprise management systems, management concepts and management methods. However, college students are not so interested in this course for lack of experience of business exercise. In order to increase the attraction of this course, the author puts forward a case teaching method by which practical cases of modern enterprise management combine with the teaching content in classroom process. Simultaneously, students can simulate every link of modern enterprise management in the experimental courses and they can design solutions and solve related problems. With this case teaching method, students' enthusiasm in learning has been greatly improved, students' grasp of classroom content is firm and students' ability to solve problems is further promoted. In a word, the case teaching method has achieved the intended purpose of teaching in this course.
\end{abstract}

\section{Introduction}

Management information system is a new interdisciplinary subject, which is formed by the research results of management science, system science, information science, computer science and modern communication technology. It is a required course of information management related majors in Colleges and universities.

Case teaching emphasizes the students' ability to understand, analyze and solve problems. It is very different from the traditional teaching purpose of knowledge imparting. In teaching methods, case teaching is more inspiring and guiding teaching, so that students can play an active role and actively participate in classroom teaching, so that students' participation in the classroom is relatively high, and makes interaction strong. Case teaching is the bridge between teaching content and practical experience through case fact. Case teaching advocates the teaching concept of "case analysis student body". There are great differences between the case teaching and the traditional teaching model. The traditional teaching mode requires teachers to be the core, and teachers are mainly taught and instilled, so that students can learn and accept knowledge, and the flow of knowledge and information is basically one-way. Even with the help of multimedia devices, it only expands the amount of information transmitted by teachers to students in unit time. In essence, it does not enable students to really participate in classroom teaching.

\section{Current Situation}

In the course of the long term teaching, the author found that students have little interest in the course of the course. It is generally believed that the "management information system" course is difficult to learn. By visiting students in class, there are two problems that need to be solved urgently. First of all, colleges and universities students are mostly high school graduates, no actual work experience and social experience, and the development and construction of management information system developers need to have flexible mind, rich experience and thoughtful and meticulous work style, these for a student in the school is difficult; secondly, teaching content too theoretical, lack of practical development case, which is difficult for students to become interested in this course. 
Through the accumulation of more than ten years of teaching experience in this course, the host of the project believes that the teaching effect can be enhanced through the application of the case teaching method.

At present, the management information system course need to be the main reason case teaching method are: first, to not go to work for college students, their lack of understanding of the operation mode of the information system to the reality of enterprises and institutions in the curriculum; secondly, theoretical courses mainly in purely theoretical explanation, students learn boring third, boring; experimental teaching in the development of the implementation system, the management of students is difficult to students caused fear; fourth, experimental teaching and theoretical teaching courses are independent of each other, cut off from the theoretical teaching and experimental teaching; finally, the management information system of the various disciplines involved in the development of rapid, concept, content, technology and method of management information system will have a greater change in different period, real-time update the case Teaching helps students to master the new knowledge in the field faster and more effectively.

\section{Reform Program}

Case teaching has a very distinctive feature, first of all, it is able to exploit the potential of the students extremely. And the traditional knowledge - oriented teaching mode, case teaching emphasizes students as the main body, and is the thinking and analysis of the common case, with different points of view and different groups of students or composed of students will reflect on the case, and by using the theories of in case of problems, put forward the corresponding solutions. Case teaching can mobilize the enthusiasm and creativity of the students to the maximum extent. College students are characterized by active thinking, and they are often not restricted by too many rules and regulations.

After consideration and analysis of the case, they may come to a number of different but constructive solutions to the same problem.

Through the discussion, students can put their views on the problems, analyzing the problems and solutions of problems were displayed, and can be solved by further analysis and discussion and debate issues and seek a better solution, so that the students can get benefit from, also realize the mutual learning.

The reason why the management information system is suitable for case teaching is that it has the following characteristics.

A) The management information system is closely connected with the practical application. The management information system emphasizes the cultivation of students' ability and emphasizes the students' ability to recognize problems, find problems, analyze problems and solve problems. That is to say, through the study of information management system, students can understand as a future decision should be clear on how to combine the advanced management ideas and advanced information technology, and solve some problems in an organization, and how to solve the problem in the role play yourself should play. The contents of management information system is very extensive, from the organization, management of information technology, can be said to be but it is very Everything is contained therein., emphasizing the practical application, in addition to the basic theoretical knowledge, it explains more is how to use information technology, combined with advanced management thought and organizational means to create more benefits and value an organization.

B) A large number of domestic and foreign management information system related cases.

One of the necessary conditions for case teaching is that the case must be adequate and appropriate. There are dozens of materials for management information system at home and abroad, and basically, each textbook provides some cases, especially in foreign textbooks, or some Chinese translation textbooks, which have very rich cases. To some extent, the cases related to the management of the information system are inexhaustible. 


\section{Reform Measures}

The case teaching of management information system has a good foundation, first of all, it is very rich in related cases. The key point of case teaching in the management information system is the following aspects:

Understand Material Essence, Re Integration of Teaching Contents, Key Chapters' Implementation of Case Teaching Method

For the specialty of information management and information system of students, this course is their university after partial course, before they have to learn the system such as data structure, database principle, computer network, management and other professional courses, a good knowledge base, development and analysis of the work and will be engaged in information system. Teachers should teach the course content step by step, reduce the weariness of the students and stimulate the interest of learning according to the order from the shallow to the deep, from the perceptual to the rational.

\section{Reasonable Design of Teaching Cases to Stimulate Students' Enthusiasm for Learning}

Case teaching is an important teaching method in the practice of modern education, is the master of the students in the basis of the basic knowledge and analysis technology, according to the teaching goal and the teaching content, teachers in the carefully planned under the guidance of the use of typical examples, the students into the case analysis of specific events, improve the identification, analysis and the ability to solve a specific problem by the way of thinking of students. Case teaching method is helpful to improve students' overall level, and use case teaching to provide students with an opportunity to understand and solve practical problems. The combination of case teaching and discussion class can achieve better learning effect. In the case of the group analysis, in a group, there are different levels of students, some students programming ability, some students' ability to analyze problems, and some of the students' ability of practical investigation is strong, through the analysis of such a problem, different students in the same group can from the other students learn their need of improvement, the overall level of students is greatly improved.

\section{Increase the Application of Project Cases in Practice Teaching and Improve the Practical} Ability of Students

Because of the strong practicality of this course, a profound understanding of the various concepts of the information system requires a rich accumulation of practical experience. Students often reflect all kinds of principles and rules in teaching materials, but in specific application environment, they don't know how to apply these principles and rules synthetically, so as to form an organic whole and form a system. Therefore, in the teaching process must pay attention to practice teaching, through the practice of culture, deepen our understanding of the basic knowledge of curriculum theory, improve understanding, observation, analysis and problem solving ability, cultivate students rigorous work style and realistic scientific attitude, make students familiar with the system engineering, and effectively improve the abilities of students and the innovation ability, a good foundation for future scientific research and practical work. In addition, excellent students should also be encouraged to actively participate in various school and outside scientific research activities, such as absorbing students' participation in Teachers' scientific research projects. It plays a very good role in cultivating the ability of outstanding students to find problems, analyze problems and solve problems, and better meet the requirements of cultivating excellent students.

Reform the Assessment Methods of the Curriculum, to test the True Level of students' learning and to analyze the Actual Effect of the Teaching of Case Law

For the traditional way of examination, it is mainly to examine the degree of the students' mastery of knowledge, and not to examine the actual application of the students. This does not reflect the practical application ability of the students. So for management information system, a relatively practical course, the main problem is what to test and how to test, especially the first problem, that is, the content of examination. In order to use this baton to guide students to focus on ability training, examination content must be changed from knowledge, skills and skills to knowledge and skills, and to focus on testing ability and quality. Examination is not a purpose, it is only a common tool to test 
the effect of learning. At the same time, we should strengthen the assessment of practical courses, and take the documents discussed in the process of the development of the system and the final development results as a part of the practice examination results. In this way, the students' learning situation can be better understood.

\section{Conclusion}

Case teaching is a new teaching method of theory and practice, in practice, often from concrete to abstract, through the analysis of specific cases to explore the inherent laws with universal guiding significance, a typical case can sometimes reflect the human understanding of the objective world from many of the truth. In the case, can find theoretical support or refute arguments, to avoid the deviation of purely theoretical research has brought to the general principle, and theory, so easy to remember, vivid image, which is beneficial to deepening the theory of learning.

In summary, the correct application of case teaching method in the teaching of management information system can significantly improve the teaching effect, has very important practical significance of teaching innovation on the course "management information system" and the students' quality education, at the same time, the reform of teaching methods, and to improve the quality of teachers will be of great benefit.

\section{Acknowledgement}

In this paper, the author was sponsored by "Teaching reform project of Southwestern University" (project number: 2017JY048).

\section{References}

[1] Q.C. Wang and J. Liu: Plication of Case Method of Teaching Management Information System, Journal of Yunnan Agricultural University, Vol.2(2008)No.5,p.72.(In Chinese)

[2] S.H. Deng, H. Wang and Y.H. Cen: An Approach to Case Teaching in the Course of MIS, Modern Educational Technology, Vol.22(2012)No.9,p.120.

[3] Y.L. Lu, H.B. Shi and M. Guo: A Probe into the Teaching Reform of MIS Course of Financial Majors in Universities, Theory and Practice of Education, Vol.35 (2015) No.12, p.49.

[4] B. Zhao: Research of the Experimental Instruction on Management Information Systems, Research and Exploration in Laboratory, Vol.30 (2011) No.4, p.108.

[5] J.H. Guo: Application of Case Teaching Method in the Course of Management Information System, Journal of East China Jiaotong University, Vol.22(2005)No.12,p.189.(In Chinese)

[6] Y. Shen, M.Y. Fan and C.H. Liu: Implementation of Associated Case Platform and its Application in MIS Teaching, Distance Education in China, Vol.25(2015)No.1,p.71.(In Chinese) 